\title{
Stage III Ovarian Germ Cell Tumor AJCC v6 and $v 7$
}

National Cancer Institute

\section{Source}

National Cancer Institute. Stage III Ovarian Germ Cell Tumor A/CC v6 and v7. NCI

Thesaurus. Code C8085.

Stage III includes: T3, NO, M0. T3: Tumor involves one or both both ovaries with microscopically confirmed peritoneal metastasis outside pelvis. NO: No regional lymph node metastasis. M0: No distant metastasis. (AJCC 6th and 7th eds.) 